\title{
The COVID-19 pandemic: an unprecedented tragedy in the battle against childhood obesity
}

Maximilian Andreas Storz, MD

Filder Hospital, Baden-Württemberg, Germany

The childhood obesity pandemic has emerged as an important public health problem in many countries. Obese children are likely to become obese adults, and adult obesity is associated with an increased risk of morbidity. Therefore, controlling the childhood obesity epidemic has become a top public health priority worldwide. The current coronavirus disease 2019 (COVID-19) pandemic may significantly impede this important mission and constitute an unprecedented tragedy in the global battle against childhood obesity. This manuscript presents evidence that the COVID-19 pandemic will aggravate the childhood obesity epidemic and lead to significant weight gain in school children by creating an unprecedented obesogenic environment. Within the last few months, many countries took uncompromising measures in response to the COVID-19 pandemic, including school closures and quarantine. While these steps are often necessary to ensure infection control, they may have a significant negative effect on children's mental and physical health. Physical, nutritional, and psychosocial factors that promote obesity in children during this special situation complementarily contribute to an unprecedented obesogenic environment. Large-scale quarantine and home confinement will impose new and unfamiliar stressors on children, thereby worsening the childhood obesity epidemic. Most importantly, adverse childhood events resulting from a predicted increase in domestic violence within the next few months will significantly contribute to this concern. The scenario presented in this review is of paramount public health importance and must be considered during future pandemic planning. Involved stakeholders, including governments, schools, and families, must make all possible efforts to minimize the impact of the COVID-19 epidemic on childhood obesity.

Key words: Childhood obesity, COVID-19, Obesogenic environment, SARS-CoV-2, Diet

\section{Key message}

Large-scale quarantine and home confinement during the coronavirus disease 2019 (COVID-19) pandemic will impose new and unfamiliar stressors on children, thereby worsening the childhood obesity epidemic. Physical, nutritional, and psychosocial factors that promote obesity in children during this special situation complementarily contribute to an unprecedented obesogenic environment. Involved stakeholders, including governments, schools, and families, must make all efforts to minimize the impact of the COVID-19 epidemic on childhood obesity.

\section{Introduction}

In December 2019, health authorities in the Hubei province of China identified a cluster of pneumonia cases of initially unknown etiology, linked to Wuhan's South China Seafood Market. ${ }^{1)}$ Within days, an increasing number of patients presented to local hospitals with serious and, in some cases, fatal pneumonia, often including pyrexia, radiological signs of acute respiratory distress syndrome, lymphopenia, and failure to resolve infection over $3-5$ days of antibiotic treatment. ${ }^{1-3)}$

Subsequent investigations identified a novel coronavirus, SARS-CoV-2 (severe acute respiratory syndrome coronavirus, ${ }^{2)}$ as the causative agent that originated in bats and was transmitted to humans through yet unknown intermediary animals in the Chinese city of Wuhan. ${ }^{1,4)}$ The number of deaths rose quickly, and on January 30, 2020, the World Health Organization officially declared the coronavirus epidemic a public health emergency of international concern. ${ }^{2,5)}$ The local Wuhan and national Chinese governments took unprecedented measures in response to this outbreak. ${ }^{6-8)}$ Schools remained closed and holidays were extended to allow people to stay away from their workplaces. Moreover, the local government promoted physical distancing, community containment, and the avoidance of crowded places. ${ }^{79}$ The Chinese government additionally discouraged public activities to prevent the infection's spread. ${ }^{10)}$

Public transportation, including trains and buses, within Wuhan was restricted and other prevention and control measures, such as isolation and quarantine, were gradually established in the city. $\left.{ }^{9} 11\right)$ Wuhan, a key transport hub located 4 hours from 


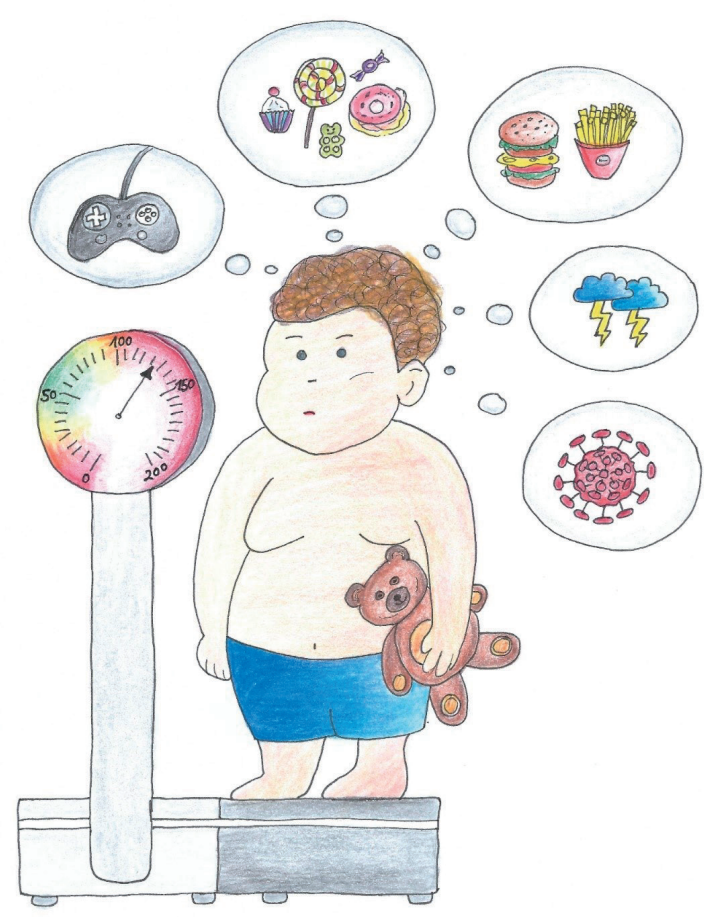

Graphical abstract. Factors that contribute to the unprecedented obesogenic environment during the coronavirus disease 2019 pandemic: a graphical abstract

Beijing by train, was shut down and its 11 million citizens were quarantined. ${ }^{1)}$

\section{Quarantine}

Quarantine is defined by the Centers for Disease Control and Prevention as the separation and restriction of the movement of people who have been exposed to a contagious disease to ascertain if they become unwell, ${ }^{12)}$ so as to reduce the risk of them infecting others. ${ }^{13)}$ Quarantine is considered an effective control measure when a disease is likely to result in a large number of secondary cases despite the isolation of symptomatic individuals. ${ }^{14,15)}$ On the other hand, quarantine is also frequently an unpleasant experience for those who undergo it. ${ }^{13)}$ The loss of freedom and control, a sense of being trapped, and ultimately the separation from loved ones may have dramatic effects. ${ }^{13,16}$ including significant psychological and psychiatric disturbances. ${ }^{17)}$ Finally, quarantine may have long-term psychological effects that can prevail for months or years. ${ }^{18,19)}$ Regardless, the potential benefits of mandatory mass quarantine must be weighed carefully against its possible psychological costs. ${ }^{13,16)}$ Therefore, considering the significant secondary and tertiary effects introduced by quarantine is of paramount importance. ${ }^{20)}$ Specifically, the coronavirus disease 2019 (COVID-19) pandemic will substantially impact another already threatening pandemic affecting most parts of the Western world and many developing countries: the childhood obesity epidemic.

\section{Childhood obesity}

Obesity is a global public health challenge ${ }^{21)}$ whose incidence has increased worldwide over the past five decades, ${ }^{22}$ reaching pandemic levels. ${ }^{23)}$ Worldwide, more than 600 million people are obese and another 2 billion are overweight. ${ }^{22}$ Children are at special risk of carrying excess weight, the prevalence of which has increased dramatically in recent decades. ${ }^{24-26)}$ Furthermore, obese children are likely to become obese adults. ${ }^{24,26,27)}$ Therefore, controlling the obesity epidemic has become a top priority for public health authorities, and community-based approaches are a cornerstone of many health interventions. ${ }^{28)}$ The current COVID-19 pandemic, however, may significantly impede the implementation of such interventions and constitute an unprecedented tragedy in the global battle against obesity. School closures and subsequent home confinement measures may negatively affect children's physical and mental health. ${ }^{10)}$ The COVID-19 pandemic will aggravate the epidemic of childhood obesity and lead to significant weight gain in school children by creating an unprecedented obesogenic environment. Psychosocial factors are the driving force behind this concern.

\section{Unprecedented obesogenic environment}

Quarantine and other types of traditional outbreak responses have been successfully employed in the past; however, they have never been executed on such a large scale. ${ }^{9)}$ School closures currently impact over $91 \%$ of the global student population. ${ }^{29}$ ) Rundle et al. ${ }^{30)}$ anticipated that the COVID-19 pandemic could double out-of-school time for many children in the United States in 2020. Children are literally forced to stay at home and are now exposed to a different environment than usual.

This exceptional situation may carry a series of negative effects that warrant further investigation. Several studies suggested that when children are out of school, during the summer months for example, they are less physically active and experience unhealthy weight gain. ${ }^{10,30-32)}$ Moreover, children lose access to almost all forms of supervised sources of physical activity as a result of school closures. ${ }^{33)}$ Contrary to public opinion, results from an American longitudinal study suggested that the risk of obesity is higher when children are out of, rather than in, school. ${ }^{34)}$

Such weight gain in childhood is of long-term concern ${ }^{30)}$ since studies have shown that obesity that develops at early age (age 5 years) is associated with both significantly higher fat mass and a higher body mass index (BMI) at age 50 years. ${ }^{35)}$ In one study, Rundle et al. ${ }^{35)}$ emphasized that participants who were obese at 5 years of age had BMI scores at 50 years of age that were 6.51 units higher (95\% confidence interval,3.67-9.35) than those with a normal weight at 5 years of age.

According to Brazendale et al., ${ }^{31)}$ obesogenic behaviors such as sedentary behavior, increased screen time, a poor diet, and irregular sleep are beneficially regulated when children follow a structured day. Although some governments have rapidly im. 
plemented emergency home schooling plans, ${ }^{10)}$ it is difficult to establish a clear structure for children during these unprecedented times. This may result in irregular sleep patterns and extensively prolonged screen times due to online class and lecture offerings (in addition to leisure screen time), leading to weight gain and reduced cardiorespiratory fitness levels. ${ }^{10)}$ Dunton et al. ${ }^{36)}$ recently raised the concern that the current negative short-term changes in sedentary behavior and physical activity may become permanently entrenched in children. Significantly increased screen time in particular may contribute to overweight and obesity in affected children. ${ }^{37-39)}$ According to Fang et al., ${ }^{37}$ a screen time of $\geq 2$ hours per day significantly increased the risk of overweight and obesity among children compared to a screen time of $<2$ hours per day. Current evidence suggests that increased screen media exposure leads to obesity in children in several ways, including increased eating while viewing. ${ }^{38)}$

It is reasonable to assume that children are exposed to less favorable diets during quarantine. ${ }^{40)}$ Given movement restrictions, people have limited access to fresh and unprocessed foods. ${ }^{41)}$ Instead, many rely on nonperishable and highly processed food options that contribute to food security. ${ }^{42)}$ However, these highly processed foods tend to be high in saturated fat, sugar, and salt. ${ }^{41,43)}$ Several large investigations have associated the consumption of such foods with adverse health outcomes, including obesity and metabolic syndrome. ${ }^{44-47)}$ A recently published Italian study found that the intakes of potato chips, red meat, and sugary drinks increased significantly during the lockdown. ${ }^{48)}$ Another recently published international investigation reported similar findings. ${ }^{49)}$ In contrast, one study also noted a positive trend: the extent to which parents supervise their child's eating increased as well. ${ }^{50)}$

Furthermore, quarantine may also have a negative psychological impact on children and their families. ${ }^{10,51-53)}$ A variety of unfamiliar stressors disrupt children's usual lifestyle, including a lack of in-person contact with classmates, friends, and teachers, feelings such as frustration and boredom, and a possible lack of personal space at home. ${ }^{10,13,32)}$ In this context, a 2013 study demonstrated that pandemic disasters and subsequent disease containment responses create traumatic conditions. ${ }^{54)}$ Such an unfamiliar and likely prolonged stressful situation could further promote unhealthy food intake through stress-related eating, thereby leading to obesity and other health problems. ${ }^{55,56)} \mathrm{Al}$ though studies of children are scarce in this particular field, one study showed that stress-related eating is highly prevalent among 16-year-old girls ${ }^{57)}$ and could be exacerbated by the current pandemic.

Many families are expected to experience financial losses or even existential threats as a consequence of the pandemic. ${ }^{10,58)}$ This might affect children in many ways; however, 2 specific aspects warrant further investigation. First, families experiencing reduced income and financial losses will encounter difficulty affording fresh and unprocessed whole foods. According to Headey and Alderman, ${ }^{59)}$ low incomes constrain what and how much food poor households can buy. Parents on a tight budget might not be able to afford fresh and healthy plant-based food options; instead, their often dramatically reduced budgets will force them to feed their children calorie-dense processed foods that are often cheaper. ${ }^{59,60)}$ This, in turn, might increase the risk of obesity and other metabolic disorders as previously explained. ${ }^{45,47)}$ Second, families will have to cope emotionally with potential economic or job losses. The COVID-19 pandemic has already led to major increases in unemployment and job insecurity rates. ${ }^{61,62)}$ Family members spend more time in close contact and, according to the World Health Organization, the current crisis will likely lead to an increase in domestic violence. ${ }^{63,64)}$ Reports from several countries, including China, Germany, Italy, and Brazil, have indicated an increase in domestic violence since the COVID-19 outbreak began. ${ }^{63,65)}$ Women in abusive relationships and their children are at particularly high risk. ${ }^{66}$ Regarding childhood obesity, the predicted increase in child abuse is the most worrisome.

Several years ago, an American study demonstrated that adverse childhood events (childhood sexual abuse) are associated with obesity and eating disorders. ${ }^{67}$ Moreover, a 2013 metaanalysis by Danese and $\operatorname{Tan}^{68)}$ including 41 studies and more than 190000 participants revealed that childhood maltreatment was associated with an elevated risk of developing obesity over the lifespan (odds ratio, 1.36; 95\% confidence interval, 1.261.47). Ultimately, Hemmingsson et al. ${ }^{69)}$ found that adverse life experiences during childhood potentially contribute to obesity by inducing mental and emotional perturbations, maladaptive coping responses, metabolic disturbances, and stress. Fig. 1 displays the close interrelation between quarantine, pandemicrelated economic hardship, and the increased risk of domestic violence.

Finally, the COVID-19 response measures, including social distancing, self-isolation, and community lockdowns, may severely limit access to health care services and preventive care in the primary care setting. ${ }^{70}$ In many countries, social work staff have to self-isolate, which strains service delivery and stretches safeguarding teams. ${ }^{71)}$ This factor may not be underestimated in the battle against domestic violence and adverse childhood events.

Table 1 briefly summarizes the factors that contribute to the unprecedented obesogenic environment children face during the

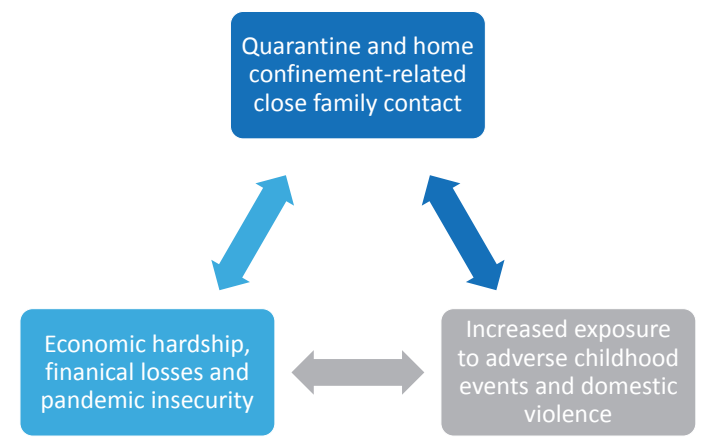

Fig. 1. The coronavirus disease 2019 pandemic: an unprecedented obesogenic environment for children at the nexus of economic hardship, quarantine, and adverse childhood experiences. 
Table 1. Overview of factors that contribute to an unprecedented obesogenic environment in children during the COVID-19 pandemic

\begin{tabular}{|c|c|c|}
\hline Factor & Increases & Decreases \\
\hline Lockdown and movement restrictions & $\begin{array}{l}\text { Sedentary lifestyle }{ }^{34)} \\
\text { Consumption of nonperishable and processed foods }{ }^{48)} \\
\text { Consumption of sweets/candy }{ }^{49)}\end{array}$ & $\begin{array}{l}\text { Access to fresh/unprocessed foods }{ }^{41)} \\
\text { Access to health care services/preventive care }{ }^{69,70)}\end{array}$ \\
\hline $\begin{array}{l}\text { Quarantine, home-confinement, } \\
\text { and social distancing }\end{array}$ & $\begin{array}{l}\text { Unfamiliar psychological stressors }{ }^{10)} \\
\text { Quarantine-related frustration and isolation }{ }^{72)} \\
\text { Stress-related eating }\end{array}$ & $\begin{array}{l}\text { In-person contact with classmates, friends, and } \\
\text { teachers }^{10)}\end{array}$ \\
\hline School closures & $\begin{array}{l}\text { Screen time }^{10)} \\
\text { Irregular sleep patterns }{ }^{31,73)} \\
\text { Unhealthy weight gain }{ }^{10,30)}\end{array}$ & $\begin{array}{l}\text { Physical activity } \\
\text { Exposure to a structured day }{ }^{31)} \\
\text { Access to supervised sources of physical activity }{ }^{33)}\end{array}$ \\
\hline $\begin{array}{l}\text { Pandemic insecurity and } \\
\text { economic hardship }\end{array}$ & $\begin{array}{l}\text { Reduced parental income and financial losses }{ }^{58,61)} \\
\text { Exposure to domestic violence and adverse childhood } \\
\text { events }^{63,65)}\end{array}$ & \\
\hline
\end{tabular}

COVID-19 pandemic.

\section{Limitations}

During major infectious disease outbreaks such as the COVID19 pandemic, quarantine can be a necessary preventive tool for infection control. This manuscript, including evidence that the COVID-19 pandemic will aggravate the childhood obesity epidemic, does not suggest that quarantine should not be used, as the psychological effects of not using quarantine and allowing the disease to spread further might be worse. ${ }^{13,74)}$ However, this manuscript presents several convincing arguments that the COVID-19 pandemic will aggravate the epidemic of childhood obesity by creating an unprecedented obesogenic environment.

While obesity has always been a problem in pandemic situations (for example, during the influenza A [H1N1] virus pandemic in 2009 and 2010), studies traditionally focused on obesity as a risk factor for an aggravated clinical course. ${ }^{75,76)}$ In contrast, studies pointing at quarantine during infectious disease pandemics as a risk factor for childhood obesity itself are scarce. On the contrary, some arguments presented in this review remain speculative.

Moreover, nobody can predict how long quarantine statuses will be maintained. Shorter quarantine periods may have only a modest effect on the physical and mental health of children compared to longer periods. However, nobody can reliably predict how long the COVID-19 pandemic will last. Thus, shorter quarantine periods might weaken the statements presented in this paper, whereas long-lasting infective control measures might strengthen them.

Finally, different countries worldwide manage the COVID-19 pandemic in different ways. There are various strategies for managing school closures and home confinement-related issues. Countries commanding large amounts of resources and an effective administrative system might be able to quickly establish emergency strategies and sustainable programs to reduce the physical and mental impact of the COVID-19 epidemic in children. In turn, this might counteract the creation of an unprecedented obesogenic environment for children.

\section{Conclusion}

This manuscript presented evidence that the COVID-19 pandemic will aggravate the childhood obesity epidemic and lead to significant weight gain in school children by creating an unprecedented obesogenic environment. It also described the physical, nutritional, and psychosocial factors that could promote obesity in children during this special situation.

The psychosocial aspects of quarantine, including new and unfamiliar stressors for children, will be the driving force that may worsen the childhood obesity epidemic. These factors include a lack of in-person contact with classmates, friends, and teachers; feelings such as frustration and boredom; and a potential lack of personal space at home. It is likely that adverse childhood events resulting from a significant increase in domestic violence within the next few months will significantly contribute to childhood obesity and eating disorders in the near future.

Physical, nutritional, and psychosocial aspects might complementarily contribute to the creation of an unprecedented obesogenic environment. Although some of the arguments in this manuscript are speculative, an increase in childhood obesity rates during the COVID-19 pandemic is a realistic scenario. One thing is for sure: children have limited ability to advocate for their needs and might suffer the most from the current pandemic.

Only the future will reveal the extent to which the COVID-19 pandemic will affect childhood obesity. Nevertheless, pandemic planning must address this concerning scenario now, and involved stakeholders (including governments, schools, and families) must make all possible efforts to minimize the impact of the COVID-19 pandemic on childhood obesity.

\section{Conflicts of interest}

No potential conflict of interest relevant to this article was reported.

\section{Acknowledgments}

The author would like to thank Maria Brommer, MD, for providing the graphical abstract for this publication. 


\section{References}

1. Lake MA. What we know so far: COVID-19 current clinical knowledge and research. Clin Med (Lond) 2020;20:124-7.

2. Huang C, Wang Y, Li X, Ren L, Zhao J, Hu Y, et al. Clinical features of patients infected with 2019 novel coronavirus in Wuhan, China. Lancet 2020;395:497-506.

3. Guan WJ, Ni ZY, Hu Y, Liang WH, Ou CQ, He JX, et al. Clinical characteristics of coronavirus disease 2019 in China. N Engl J Med 2020; 382:1708-20.

4. Singhal T. A review of coronavirus disease-2019 (COVID-19). Indian J Pediatr 2020;87:281-6.

5. Guo YR, Cao QD, Hong ZS, Tan YY, Chen SD, Jin HJ, et al. The origin, transmission and clinical therapies on coronavirus disease 2019 (COVID-19) outbreak - an update on the status. Mil Med Res 2020;7:11.

6. Chen S, Yang J, Yang W, Wang C, Bärnighausen T. COVID-19 control in China during mass population movements at New Year. Lancet 2020; 395:764-6.

7. Prem K, Liu Y, Russell TW, Kucharski AJ, Eggo RM, Davies N, et al. The effect of control strategies to reduce social mixing on outcomes of the COVID-19 epidemic in Wuhan, China: a modelling study. Lancet Public Health 2020;5:e261-70.

8. Xiao Y, Torok ME. Taking the right measures to control COVID-19. Lancet Infect Dis 2020;20:523-4.

9. Wu Z, McGoogan JM. Characteristics of and important lessons from the coronavirus disease 2019 (COVID-19) outbreak in China: summary of a report of 72314 cases from the Chinese Center for Disease Control and Prevention. JAMA 2020;323:1239-42.

10. Wang G, Zhang Y, Zhao J, Zhang J, Jiang F. Mitigate the effects of home confinement on children during the COVID-19 outbreak. Lancet 2020;395:945-7.

11. Wang H, Wang Z, Dong Y, Chang R, Xu C, Yu X, et al. Phase-adjusted estimation of the number of coronavirus disease 2019 cases in Wuhan, China. Cell Discov 2020;6:10.

12. Centers for Disease Control and Prevention. Quarantine and Isolation [Internet]. Atlanta (GA): Centers for Disease Control and Prevention; [2020 Jun 14]. Available from: https://www.cdc.gov/quarantine/index. html.

13. Brooks SK, Webster RK, Smith LE, Woodland L, Wessely S, Greenberg N, et al. The psychological impact of quarantine and how to reduce it: rapid review of the evidence. Lancet 2020;395:912-20.

14. Coomes EA, Leis JA, Gold WL. CMAJ 2020:192(13). https://doi.org/ 10.1503/cmaj.200393.

15. Day T, Park A, Madras N, Gumel A, Wu J. When is quarantine a useful control strategy for emerging infectious diseases? Am J Epidemiol 2006;163:479-85.

16. Rubin GJ, Wessely S. The psychological effects of quarantining a city. BMJ 2020;368:m313.

17. Sood S. Psychological effects of the coronavirus disease-2019 pandemic. RHiME 2020;7:23-6.

18. Jeong H, Yim HW, Song YJ, Ki M, Min JA, Cho J, et al. Mental health status of people isolated due to Middle East Respiratory Syndrome. Epidemiol Health 2016;38:e2016048.

19. Liu X, Kakade M, Fuller CJ, Fan B, Fang Y, Kong J, et al. Depression after exposure to stressful events: lessons learned from the severe acute respiratory syndrome epidemic. Compr Psychiatry 2012;53:15-23.

20. Barbisch D, Koenig KL, Shih FY. Is there a case for quarantine? Perspectives from SARS to Ebola. Disaster Med Public Health Prep 2015; 9:54753.

21. Foss B, Dyrstad SM. Stress in obesity: cause or consequence? Med Hypotheses 2011;77:7-10.

22. Bradley P. Refined carbohydrates, phenotypic plasticity and the obesity epidemic. Med Hypotheses 2019;131:109317.

23. Blüher M. Obesity: global epidemiology and pathogenesis. Nat Rev
Endocrinol 2019;15:288-98.

24. Di Cesare M, Sorić M, Bovet P, Miranda JJ, Bhutta Z, Stevens GA, et al. The epidemiological burden of obesity in childhood: a worldwide epidemic requiring urgent action. BMC Med 2019;17:212.

25. Kumar S, Kelly AS. Review of childhood obesity: from epidemiology, etiology, and comorbidities to clinical assessment and treatment. Mayo Clin Proc 2017;92:251-65.

26. Llewellyn A, Simmonds M, Owen CG, Woolacott N. Childhood obesity as a predictor of morbidity in adulthood: a systematic review and metaanalysis. Obes Rev 2016;17:56-67.

27. Freedman DS, Khan LK, Dietz WH, Srinivasan SR, Berenson GS. Relationship of childhood obesity to coronary heart disease risk factors in adulthood: the Bogalusa Heart Study. Pediatrics 2001;108:712-8.

28. Walls HL, Peeters A, Proietto J, McNeil JJ. Public health campaigns and obesity - a critique. BMC Public Health 2011;11:136.

29. COVID-19 educational disruption and response [Internet]. Paris: UNESCO; 2020 [2020 Jun 14]. Available from: https://en.unesco.org/ covid19/educationresponse.

30. Rundle AG, Park Y, Herbstman JB, Kinsey EW, Wang YC. COVID-19related school closings and risk of weight gain among children. Obesity (Silver Spring) 2020;28:1008-9.

31. Brazendale K, Beets MW, Weaver RG, Pate RR, Turner-McGrievy GM, Kaczynski AT, et al. Understanding differences between summer vs. school obesogenic behaviors of children: the structured days hypothesis. Int J Behav Nutr Phys Act 2017;14:100.

32. Ghosh R, Dubey MJ, Chatterjee S, Dubey S. Impact of COVID -19 on children: special focus on the psychosocial aspect. Minerva Pediatr 2020; 72:226-35.

33. Rothstein R, Olympia RP. School nurses on the front lines of healthcare: the approach to maintaining student health and wellness during COVID19 school closures. NASN Sch Nurse 2020;35:269-75.

34. von Hippel PT, Workman J. From Kindergarten Through Second Grade, U.S. Children's Obesity Prevalence Grows Only During Summer Vacations. Obesity (Silver Spring) 2016;24:2296-300.

35. Rundle AG, Factor-Litvak P, Suglia SF, Susser ES, Kezios KL, Lovasi GS, et al. Tracking of obesity in childhood into adulthood: effects on body mass index and fat mass index at age 50. Child Obes 2020;16:226-33.

36. Dunton GF, Do B, Wang SD. Early effects of the COVID-19 pandemic on physical activity and sedentary behavior in children living in the U.S. BMC Public Health 2020;20:1351.

37. Fang K, Mu M, Liu K, He Y. Screen time and childhood overweight/ obesity: A systematic review and meta-analysis. Child Care Health Dev 2019;45:744-53.

38. Robinson TN, Banda JA, Hale L, Lu AS, Fleming-Milici F, Calvert SL, et al. Screen media exposure and obesity in children and adolescents. Pediatrics 2017;140(Suppl 2):S97-101.

39. Nagata JM, Abdel Magid HS, Pettee Gabriel K. Screen time for children and adolescents during the coronavirus disease 2019 pandemic. Obesity (Silver Spring) 2020;28:1582-3.

40. Calcaterra V, Vandoni M, Pellino VC, Cena H. Special attention to diet and physical activity in children and adolescents with obesity during the coronavirus disease-2019 pandemic. Front Pediatr 2020;8:407.

41. Food and nutrition during self-quarantine: what to choose and how to eat healthily 2020. Copenhagen (Denmark): WHO Regional Office for Europe UN City; [cited 2020 Jun 14]. Available from: http://www. euro.who.int/en/health-topics/disease-prevention/nutrition/news/news/ 2020/3/food-and-nutrition-during-self-quarantine-what-to-choose-andhow-to-eat-healthily.

42. Weaver CM, Dwyer J, Fulgoni VL 3rd, King JC, Leveille GA, MacDonald RS, et al. Processed foods: contributions to nutrition. Am J Clin Nutr 2014;99:1525-42.

43. Poti JM, Braga B, Qin B. Ultra-processed food intake and obesity: what really matters for health-processing or nutrient content? Curr Obes Rep 2017;6:420-31.

44. Lawrence MA, Baker PI. Ultra-processed food and adverse health outcomes. BMJ 2019;365:12289.

45. Laster J, Frame LA. Beyond the calories-is the problem in the processing? 
Curr Treat Options Gastroenterol 2019;17:577-86.

46. Monteiro CA, Moubarac JC, Levy RB, Canella DS, Louzada MLDC, Cannon G. Household availability of ultra-processed foods and obesity in nineteen European countries. Public Health Nutr 2018;21:18-26.

47. Louzada ML, Baraldi LG, Steele EM, Martins AP, Canella DS, Moubarac JC, et al. Consumption of ultra-processed foods and obesity in Brazilian adolescents and adults. Prev Med 2015;81:9-15.

48. Pietrobelli A, Pecoraro L, Ferruzzi A, Heo M, Faith M, Zoller T, et al. Effects of COVID-19 lockdown on lifestyle behaviors in children with obesity living in Verona, Italy: a longitudinal study. Obesity (Silver Spring) 2020;28:1382-5.

49. Ruiz-Roso MB, de Carvalho Padilha P, Mantilla-Escalante DC, Ulloa N, Brun P, Acevedo-Correa D, et al. Covid-19 confinement and changes of adolescent's dietary trends in Italy, Spain, Chile, Colombia and Brazil. Nutrients 2020;12:1807.

50. Adams EL, Caccavale LJ, Smith D, Bean MK. Food insecurity, the home food environment, and parent feeding practices in the era of COVID-19. Obesity (Silver Spring) 2020;28:2056-63.

51. Liu JJ, Bao Y, Huang X, Shi J, Lu L. Mental health considerations for children quarantined because of COVID-19. Lancet Child Adolesc Health 2020;4:347-9.

52. Hawryluck L, Gold WL, Robinson S, Pogorski S, Galea S, Styra R. SARS control and psychological effects of quarantine, Toronto, Canada. Emerg Infect Dis 2004;10:1206-12.

53. Yeasmin S, Banik R, Hossain S, Hossain MN, Mahumud R, Salma N, et al. Impact of COVID-19 pandemic on the mental health of children in Bangladesh: a cross-sectional study. Child Youth Serv Rev 2020;117: 105277.

54. Sprang G, Silman M. Posttraumatic stress disorder in parents and youth after health-related disasters. Disaster Med Public Health Prep 2013; 7:105-10.

55. Rasheed N. Stress-associated eating leads to obesity. Int J Health Sci (Qassim) 2017;11:1-2.

56. Torres SJ, Nowson CA. Relationship between stress, eating behavior, and obesity. Nutrition 2007;23:887-94.

57. Jääskeläinen A, Nevanperä $\mathrm{N}$, Remes J, Rahkonen F, Järvelin MR, Laitinen J. Stress-related eating, obesity and associated behavioural traits in adolescents: a prospective population-based cohort study. BMC Public Health 2014;14:321.

58. Hossain MM, Sultana A, Purohit N. Mental health outcomes of quarantine and isolation for infection prevention: a systematic umbrella review of the global evidence. Epidemiol Health 2020;42:e2020038.

59. Headey DD, Alderman HH. The relative caloric prices of healthy and unhealthy foods differ systematically across income levels and continents. J Nutr 2019;149:2020-33.

60. NPR. Why processed food is cheaper than healthier options [Internet]. Washington, DC: NPROrg; c2020 [cited 2020 Jun 14]. Available from: https://www.npr.org/2013/03/01/173217143/why-process-food-ischeaper-than-healthier-options.

61. Pérez-Escamilla R, Cunningham K, Moran VH. COVID-19 and maternal and child food and nutrition insecurity: a complex syndemic. Matern Child Nutr 2020;16:e13036.

62. Wilson JM, Lee J, Fitzgerald HN, Oosterhoff B, Sevi B, Shook NJ. Job insecurity and financial concern during the COVID-19 pandemic are associated with worse mental health. J Occup Environ Med 2020;62:68691.

63. World Health Organization. WHO Director-General's opening remarks at the media briefing on COVID-19 - 3 April 2020 [Internet]. Geneva (Switzerland): World Health Organization; 2020 Apr [cited 2020 Jun 14]. Available from: https:/www.who.int/dg/speeches/detail/who-directorgeneral-s-opening-remarks-at-the-media-briefing-on-covid-19--3april-2020.

64. Storz MA. Child abuse: a hidden crisis during COVID-19 quarantine. J Paediatr Child Health 2020;56:990-1.

65. Graham-Harrison E, Giuffrida A, Smith H, Ford L. Lockdowns around the world bring rise in domestic violence [Internet]. London: The Guardian 2020; [cited 2020 Jun 14]. Available from: https://www.theguardian. com/society/2020/mar/28/lockdowns-world-rise-domestic-violence.

66. Cobbe E. Self-quarantine amid coronavirus pandemic will likely lead to increase in domestic violence, WHO warns [Internet]. New York (NY): CBS NEWS; 2020 Apr [cited 2020 Jun 14]. Available from: https:// www.cbsnews.com/news/coronavirus-self-quarantine-will-likely-lead-toincrease-in-domestic-violence-world-health-organization-warns/.

67. Fuemmeler BF, Dedert E, McClernon FJ, Beckham JC. Adverse childhood events are associated with obesity and disordered eating: results from a U.S. population-based survey of young adults. J Trauma Stress 2009;22:329-33.

68. Danese A, Tan M. Childhood maltreatment and obesity: systematic review and meta-analysis. Mol Psychiatry 2014;19:544-54.

69. Hemmingsson E, Johansson K, Reynisdottir S. Effects of childhood abuse on adult obesity: a systematic review and meta-analysis. Obes Rev 2014;15:882-93.

70. Akseer N, Kandru G, Keats EC, Bhutta ZA. COVID-19 pandemic and mitigation strategies: implications for maternal and child health and nutrition. Am J Clin Nutr 2020;112:251-6.

71. Green P. Risks to children and young people during covid-19 pandemic. BMJ 2020;369:m1669.

72. Mediouni M, Madiouni R, Kaczor-Urbanowicz KE. COVID-19: How the quarantine could lead to the depreobesity. Obes Med 2020:100255.

73. Bates LC, Zieff G, Stanford K, Moore JB, Kerr ZY, Hanson ED, et al. COVID-19 Impact on behaviors across the 24-hour day in children and adolescents: physical activity, sedentary behavior, and sleep. Children (Basel) 2020;7:138.

74. Hull HF. SARS control and psychological effects of quarantine, Toronto, Canada. Emerg Infect Dis 2005;11:354; author reply 354-5.

75. Plessa E, Diakakis P, Gardelis J, Thirios A, Koletsi P, Falagas ME. Clinical features, risk factors, and complications among pediatric patients with pandemic influenza A (H1N1). Clin Pediatr (Phila) 2010;49:777-81.

76. Kim CO, Nam CM, Lee DC, Chang J, Lee JW. Is abdominal obesity associated with the 2009 influenza A (H1N1) pandemic in Korean schoolaged children? Influenza Other Respir Viruses 2012;6:313-7.

How to cite this article: Storz MA. The COVID-19 pandemic: an unprecedented tragedy in the battle against childhood obesity. Clin Exp Pediatr 2020;63:477-82. https://doi.org/ 10.3345/cep.2020.01081 